\title{
Perspectiva analítica y comparada del Estado de Cosas Inconstitucional en el sistema carcelario y penitenciario en Colombia
}

Analytical and comparative perspective on the Unconstitutional State of Affairs in the prison and penitentiary system in Colombia

Autores: Omar Huertas Díaz, Christian Benítez Núñez y

Filiberto Eduardo R. Manrique Molina

DOI: http://doi.org/10.25058/7794600X.1796 


\title{
PERSPECTIVA ANALÍTICA Y COMPARADA DEL ESTADO DE COSAS INCONSTITUCIONAL EN EL SISTEMA CARCELARIO Y PENITENCIARIO EN COLOMBIA*
}

\author{
Analytical and comparative perspective on the \\ Unconstitutional State of Affairs in the prison and penitentiary \\ system in Colombia
}

\section{Perspectiva analítica e comparativa do estado inconstitucional de coisas no sistema carcerário e penitenciário da Colômbia}

Omar Huertas Díaz ${ }^{a}$ ohuertasd@unal.edu.co

Christian Benítez Núñez ${ }^{b}$

christianbenitez@uaem.mx

Filiberto Eduardo R. Manrique Molinac filiberto.manriquemol@uaem.edu.mx

Fecha de recepción: 06 de abril de 2020 Fecha de revisión: 21 de abril de 2020 Fecha de aceptación: 23 de abril de 2020

DOI: http://doi.org/10.25058/1794600X.1796

Para citar esta colaboración especial:

Huertas Díaz, O.; Benítez Nuñez, C. y Manrique Molina, F. E. (2020). Perspectiva analítica y comparada del Estado de Cosas Inconstitucional en el sistema carce-

lario y penitenciario en Colombia. Revista Misión Jurídica, 13, (19). 234-251.

\footnotetext{
* Artículo resultado de investigación en el Grupo de Investigación "Red Internacional de Política Criminal Extrema Ratio UN" Reconocido y Clasificado Minciencias 2018 en A1 en el marco de cooperación de la Estancia Postdoctoral (2018-2020) financiada por CONACYT - México.

a. Abogado, PhD. en Derecho, especialista en Derecho Penal, Curso Postdoctoral en Derecho, profesor asociado e investigador senior de la Universidad Nacional de Colombia; Magister en Derechos Humanos, Estado de Derecho y Democracia en Iberoamérica, de la Universidad de Alcalá (España); Magíster en Derecho Penal, de la Universidad Libre; Ph.D. en Ciencias de la Educación de la Universidad Simón Bolívar. Magíster en Educación de la Universidad Pedagógica Nacional. Director Grupo de Investigación "Red Internacional de Política Criminal Extrema Ratio UN" Reconocido y Clasificado Minciencias 2018 en A1.

b. Doctor en Derecho y Globalización por la Universidad Autónoma de Morelos dentro del Programa Nacional de Posgrados de Calidad - CONACYT, durante el 2018-2020 realiza estudios posdoctorales en la Universidad Nacional de Colombia. Se ha desempeñado profesionalmente -como funcionario judicial, abogado postulante y docente universitario, impartiendo cursos y conferencias en América Latina, publicando sus investigaciones en más de 18 libros y revistas científicas nacionales e internacionales. Actualmente se desempeña como Director Ejecutivo del Centro Interamericano de Investigación en Derechos Humanos y Litigio Estratégico A.C., perteneciendo al Sistema Nacional de Investigadores CONACYT - México, reconocido como investigador junior por COLCIENCIAS 2018, combinando tanto su formación teórica como práctica.

c. Ph.D. en Derecho y Globalización por la Facultad de Derecho y Ciencias Sociales de la Universidad Autónoma del Estado de Morelos-México; Maestro en Derecho, abogado, realiza estudios de postdoctorado en la Facultad de Derecho, Ciencias Políticas y Sociales de la Universidad Nacional de Colombia-sede Bogotá; reconocido por el Sistema Nacional de Investigadores SNICONACYT-México e Investigador Jr. MINCIENCIAS- 2018 Colombia.
} 


\section{RESUMEN}

El presente artículo de investigación analizó la declaratoria del Estado de Cosas Inconstitucional (ECI) en el sistema carcelario y penitenciario en Colombia, desarrollo de la Corte Constitucional que sirve como remedio y limitación a la violación generalizada de derechos consagrados a nivel constitucional. La Corte, como guardiana de la Constitución, ha desarrollado de manera progresiva en sus sentencias la figura ECI, con la finalidad de obligar a las autoridades colombianas a causar la reconstrucción, reorganización o ajustes de las instituciones penitenciarias, con el fin de poder superar aquellos factores estructurales que pueden ser las causas de un patrón de abusos de las personas en reclusión.

\section{PALABRAS CLAVE}

Constitución, Derechos Humanos, Estado de Cosas Inconstitucional, Hacinamiento.

\section{ABSTRACT}

This research article analyzed the declaration of the Unconstitutional State of Affairs (ECI) in the prison and penitentiary system in Colombia, the development of the Constitutional Court that functions as a remedy as well as limitation to the general violation of the rights embodied at a constitutional level. The Court, guardian of the Constitution, has developed a progressive way in its judgements of the ECI figure, aiming to oblige the Colombian authorities to cause reconstruction, reorganization or adjustments in penitentiary institutions with the purpose of overcoming those structural factors that can be the cause of a pattern of abuse of people in jail.

\section{KEY WORDS}

Constitution, Human Rights, Unconstitutional state of affairs, overpopulation.

\section{RESUMO}

Este artigo de pesquisa analisou a declaração do Estado de Coisas Inconstitucional (ECI) no sistema prisional e penitenciário da Colômbia, produto do desenvolvimento do Tribunal Constitucional que serve como remédio e limitação à violação generalizada de direitos consagrados na esfera constitucional. 0 Tribunal, como guardião da
Constituição, tem desenvolvido progressivamente a figura do ECI em suas sentenças, a fim de obrigar as autoridades colombianas a promover a reconstrução, reorganização ou ajustes das instituições penitenciárias, a fim de superar os fatores estruturais que podem ser as causas de um padrão de abuso de pessoas na prisão.

\section{PALAVRAS-CHAVE}

Constituição; direitos humanos; estado inconstitucional de coisas; superlotação.

\section{METODOLOGÍA}

En el presente artículo se utilizan dos perspectivas metodológicas: la analítica y comparativa. La perspectiva analítica permite buscar, analizar y descomponer todos los conceptos y definiciones que comprende la declaratoria del Estado de Cosas Inconstitucional (ECI) y de los temas que se pretenden abarcar, aclarar los conceptos, sus alcances y límites desde un punto de vista crítico y propositivo. Con la perspectiva comparativa se buscará la comparación sistemática de la línea jurisprudencial desarrollada por la Corte Constitucional, dicho análisis comparativo tiene la finalidad de establecer semejanzas y diferencias entre los derechos que buscan proteger, a partir de la pregunta ¿cómo la declaratoria del estado de cosas inconstitucional redirecciona el actuar del Estado hacia el respeto y garantía de los derechos humanos en el sistema carcelario y penitenciario?

\section{INTRODUCCIÓN}

El derecho de origen jurisprudencial guarda una característica, la cual lo hace especial, este tipo de derecho tal y como lo señala Diego López:

[S]e logra de manera lenta y progresiva por cuanto es necesario, para lograr la identificación de la subregla vigente en un momento dado [...] hacer un análisis temporal $\mathrm{y}$ estructural de varias sentencias que se relacionan entre sí (López, 2006: 139).

Es importante atender ello, pues el presente artículo funda su teleología en hacer el esfuerzo por presentar un análisis de los aspectos más relevantes del contenido de seis sentencias que tratan violaciones masivas, mediante las cuales la Corte Constitucional colombiana dio 
génesis y ha venido evolucionando en sus nuevos desarrollos por vía jurisprudencial. Nos referimos a la figura clave denominada Estado de Cosas Inconstitucional (en adelante ECI), en el estudio que nos ocupa, en relación con la crisis del sistema penitenciario y carcelario de Colombia.

Conviene señalar que "son las palabras del legislador más la interpretación que los jueces hacen de ellas, en aras de fijar su sentido preciso para facilitar la comprensión del mensaje normativo" (Archila \& Hernández, 2015), en ese sentido las decisiones que analizaremos han sido dictadas a lo largo de un periodo de más de veinte años, lo que nos permite corroborar que la creación de derecho mediante decisiones judiciales se logra de manera lenta y pausada, pero progresiva.

Por esta razón, expondremos los principales razonamientos que dieron pie a una línea jurisprudencial definida en todas y cada una de estas sentencias, lo cual servirá como base para identificar los desarrollos jurisprudenciales que han tenido como teleología el contar con un remedio y limitación a la violación generalizada de derechos consagrados a nivel constitucional y obligar a los gobiernos de los Estados a causar la reconstrucción, reorganización o ajustes de las instituciones penitenciarias (R. Manrique \& Huertas, 2018), para efecto de poder superar aquellos factores estructurales que pueden significar las causas de un patrón de abusos de los derechos más básicos de todas las personas sin excepción que se encuentran en prisión.

Importante señalar que la declaratoria del ECI es un instrumento de carácter imperativo que pretende reivindicar la demanda de justicia de los sectores de la población más vulnerable, respecto de aquellas instituciones gubernamentales que trasgreden con carácter general y reiterado los derechos de una multitud de personas; en las cuales se han detectado ciertos factores contextuales y estructurales, tales como lo son omisiones legislativas, administrativas o de carácter presupuestal que acarrean amenazas y trasgresiones sobre el ejercicio de derechos constitucionales.

Dicha declaratoria, les ha permitido a los magistrados que integran la Corte Constitucional de Colombia ejercer un auténtico activismo judicial, para salvaguardar la lista de derechos constitucionales y en algunos casos la norma supra, permitiéndoles no solo el ordenar acciones de corrección de un conjunto de órganos e instituciones estatales, sino además coordinar y verificar la reforma de éstas, permitiéndole a los tribunales "volver una y otra vez sobre las practicas institucionales y evaluarlas a la luz de los ideales constitucionales" (Fiss, 2013: 92), con el objetivo de garantizar ese amplio catálogo de derechos vigente de las personas en reclusión.

Ese activismo judicial de la Corte Constitucional, al momento de dictar sus sentencias y durante la ejecución o supervisión de cumplimiento, se ha enfrentado a ciertas críticas $\mathrm{y}$ tensiones con los otros poderes estatales, los cuales han alegado que dichas sentencias constituyen una invasión de sus esferas de actuación. Lamentablemente tales tensiones causan que "el desarrollo jurisprudencial no siempre responda a la velocidad de las necesidades sociales, pues la jurisprudencia se origina a partir de la exigibilidad judicial de los derechos humanos en su integralidad" (Huertas, R. Manrique, \& Benítez, 2019: 24).

Atendiendo a ello, en este texto se comparte la idea de Lawrence Sager según la cual "cualquier argumento relacionado con los llamados derechos de primera generación también será un argumento para los derechos sociales" (Sager, 2013: 305), puesto que toda decisión judicial debe atender a los principios que maximizan y amplifican la interpretación se derivan de los derechos fundamentales, en especial de aquellas en condición de reclusión, como por ejemplo el principio de interdependencia e indivisibilidad.

En este sentido, no podría ser válido un argumento que, en clave, sostenga sólidamente que la declaratoria del ECI solo corresponde exclusivamente a la infracción de los derechos de carácter social, o de una determinada naturaleza, como lo son los políticos, económicos etc., ya que los derechos humanos guardan una muy cercana interrelación. En consecuencia, la violación de unos derechos específicos vulnera de manera inmediata a otros, lo que se asimila a un efecto dominó (Benítez, 2014: 74). Es decir, la figura de declaración del ECI se refiere al hallazgo por parte de las autoridades judiciales de una cadena sucesiva y quizá masiva de afectaciones a un conjunto de derechos fundamentales, las cuales son contrarias a los preceptos y espíritu 
constitucional y supra, por ello, no pueden ser admitidas, mucho menos consentidas dentro de un Estado social, democrático y de derecho. Por lo anterior, la solución que han elaborado los más altos tribunales es la puesta en marcha de una serie de acciones ordenadas, coordinadas, solidarias y mancomunadas de los poderes y autoridades del Estado.

Cabe destacar que la Corte como guardiana de la constitución en Colombia, es una de las cortes más proactivas en la región, sus decisiones la han situado a la vanguardia del neoconstitucionalismo, debido a la emisión de un gran número de sentencias para hacer frente $\mathrm{y}$ corregir las sistemáticas y graves infracciones constitucionales; de allí la relevancia del importante desarrollo del derecho por vía jurisprudencial que ha acuñado la corte en los últimos años, que "se perfila como una estrategia legitima para el cambio social y como un mecanismo alternativo del propio estado constitucional para satisfacer las demandas relegadas por la ineficacia del poder legislativo y de la administración" (Bernal, 2005: 19).

De sus desarrollos como guardiana de la Constitución, es que "tiene su origen la figura del ECI, cuya finalidad representa la garantía de protección auténtica de los derechos de miles de personas en las prisiones, cuyas violaciones son de carácter general y sus causas guardan un carácter de tipo estructural" (Huertas, R. Manrique, \& Benítez, 2019: 24). Este modelo de constitucionalismo parte de dos elementos principales de la Constitución: "el diseño de la forma del Estado y la declaración de los derechos que conforman principios y programas políticos" (Guastini, 2010: 44). Sin embargo, el cumplimiento de estos elementos depende de que cuenten con una garantía jurisdiccional efectiva.

\section{EL NUEVO CONSTITUCIONALISMO EN AMÉRICA LATINA}

Dentro de un contexto democrático, una constitución representa la ley suprema en la que una sociedad establece sus bases políticas, jurídicas y sociales; las cuales se expresan en reglas y principios inviolables para consolidar un proyecto de nación ${ }^{1}$. Asimismo, en esta ley suprema se establece un modelo de ejercicio

1. Ver “Entre reglas y principios" (Jiménez, 2008, págs. 15-50). y control del poder, a través de medios normalmente procesales- orientados a la restitución del orden ante cualquier acto abusivo o autoritario (Benítez, 2013: 138).

Lo anterior ha traído como consecuencia el surgimiento del constitucionalismo, comprendiéndolo dentro de dos dimensiones,

la que corresponde a un 1) sistema jurídico, es decir, un conjunto de límites y vínculos, tanto formales como sustanciales; y, la que corresponde a una 2) teoría del Derecho, relativa a la validez de las normas jurídicas, atendiendo a la estricta coherencia de los contenidos con los principios de justicia establecidos en la ley suprema (Ferrajoli, 2012: 16).

Ahora bien, la positivización de los principios constitucionales en normas supra ordenadas, no solo imponen un límite al poder legislativo, sino que surge aquello que Ferrajoli (2018) ha denominado "el paradigma de la democracia constitucional", y, tiende a desarrollarse a partir de un constitucionalismo articulado de la siguiente manera:

1) Constitucionalismo social agregado al liberal.

2) Constitucionalismo de derecho privado añadido al de derecho público.

3) Constitucionalismo de los bienes fundamentales junto al de los derechos fundamentales.

4) Constitucionalismo supranacional o de derecho internacional además del estatal (Ferrajoli, 2018: 27).

En ese mismo sentido, Prieto Sanchís advierte que este constitucionalismo -al que califica de fortísimo-, representa la articulación de dos premisas, una 1) material, en la que se incorpora un contenido sustantivo a partir de valores, principios y derechos, imponiendo límites y direccionando a las autoridades hacia aquello que deben hacer; mientras que la premisa 2) formal, implica que las normas constitucionales cuentan con una especial fuerza jurídica que se traduce en la imposición de una regulación directa de su objeto normativo, y en la garantía judicial, inclusive frente al actuar del propio poder legislativo (Prieto, 2013: 12-13). 
Cabe señalar que esta tendencia no es exclusiva de un continente o país, sino que representa un proceso formalizado en la "Declaración Universal de los Derechos Humanos" como manifestación contra las más aberrantes acciones autoritarias que dieron lugar a los conflictos bélicos más degradantes, nos referimos a las dos guerras mundiales y la reivindicación de los derechos humanos, a partir de su reconocimiento supranacional.

Sin embargo, este apartado se centra en realizar un análisis de un desarrollo original del denominado constitucionalismo latinoamericano, el cual nos indica que estamos ante un derecho vivo y evolutivo, el cual refuerza los ideales de democracia en la región con su desarrollo por vía jurisprudencial, así como por los efectos del movimiento reformatorio a sus constituciones o en su caso la promulgación de nuevos diseños de las constituciones en las últimas tres décadas, caracterizándose por su distanciamiento de los regímenes autoritarios que tuvieron lugar durante casi todo el siglo XX.

Se ha de reforzar lo anteriormente planteado con las afirmaciones de Collin Crawford y Daniel Bonilla, al precisar de manera sintetizada las reformas constitucionales en América Latina durante las últimas décadas, resaltando las dimensiones formales y sustanciales:

El derecho constitucional latinoamericano ha sufrido una profunda transformación en los últimos veinticinco años. Por un lado, un número significativo de países en América Latina reformó o emitió nuevas constituciones para consolidar o expandir sus democracias liberales. Las transformaciones constitucionales en Brasil (1988), Colombia (1991), Paraguay (1992), Perú (1993), Argentina (1995), Ecuador (1998) y Chile (2005) tenían, entre otros objetivos, el objetivo de volver a legitimar sus sistemas políticos, establecer un nuevo equilibrio entre las ramas del gobierno, ampliar sus declaraciones de derechos o modernizando sus instituciones políticas y legales (Crawford \& Bonilla, 2018, s.p.).

Asimismo, cobra especial relevancia el avance constitucional en países como Venezuela (1999),
Ecuador (2008) y Bolivia (2009) ${ }^{2}$, al margen de las condiciones políticas a las que recientemente se han o están enfrentado dichos países, han reconocido un catálogo de derechos partiendo del reconocimiento del pluralismo, de principios y valores con base en la madre naturaleza; así como la reforma constitucional en México (2011), en la que se adoptan los principios "pro persona y de interpretación conforme" ante el reconocimiento de un parámetro de regularidad constitucional, tomando en cuenta tratados internacionales en materia de derechos humanos.

Con lo anterior, se ha pretendido demostrar el desarrollo de un constitucionalismo en América Latina compuesto de elementos formales presentes desde sus inicios-, y elementos materiales - siendo novedosos al imponer límites y cuestionar la validez de las propias normas-; elementos complementarios que permiten a los operadores del derecho -ya sea en sede judicial o legislativa-, trasladar los derechos reconocidos en el papel, a la realidad.

\section{EL NUEVO CONSTITUCIONALISMO COLOMBIANO A PARTIR DE 1991}

En Colombia durante un poco más de un siglo, estuvo vigente la Constitución Política de 1886, independientemente de las reformas a lo largo de los años, el texto de dicha ley suprema representó la base del orden jurídico de aquel entonces.

Frente a la complicada realidad que se vivía desde finales de 1980 e inicios de la década siguiente en áreas como seguridad, estabilidad económica, participación política, pobreza y educación, se planteó la necesidad de una nueva Constitución en la que se estableciera un nuevo modelo de Estado para hacer frente a tan grandes retos.

En ese sentido, Oscar Mejía afirma que "la Constitución Política de Colombia de 1991, estableció un proyecto social-democrático de modernidad política, de inclusión más pluralista y bajo lineamientos tolerantes, enfrentándose a todas aquellas prácticas comunes

2. Ver "De los derechos ambientales a los derechos de la naturaleza: racionalidades emancipadoras del derecho ambiental y nuevas narrativas constitucionales en Colombia Ecuador Y Bolivia" (Gómez, L. \& León, M. A., 2015). 
y fines incongruentes derivados de la carta iusfundamental de 1886" (Mejía, 2012: 186).

Resulta entonces conveniente plantear el siguiente interrogante ¿Cuáles son el conjunto de peculiaridades que se presentan en el constitucionalismo colombiano a partir del año de 1991? Para estar en posibilidad de encontrar la carta de navegación jurídica que nos ayude a responder este cuestionamiento, se ha de precisar que la Constitución representa un texto democrático (artículos 3 y 103), participativo (artículos 1, 7, 10, 16, 18, 19, 171, 176, 286, 246), pluralista (artículos 1, 7, 10, 16, 18, 19, 171, 176, 286,246 ), y sobre todo, garantista (artículos 4, 31, $40,86,87,88,184$ y 241 ).

En atención a lo anterior, Diego López ha advertido que otra de las transformaciones más significativas tuvo que ver con la creación de una jurisdicción constitucional independiente y la acción de tutela como medio de control constitucional, obligando a poner especial atención a los problemas relacionados con las "fuentes, interpretación y la legitimidad en el derecho" (López, 2006: XVIII).

Estos cambios corroboran esa dimensión sustancial del nuevo constitucionalismo latinoamericano, además del reconocimiento del bloque de constitucionalidad, de conformidad con el artículo 93 de la carta política, y la incorporación de principios como "interpretación conforme, pro persona, universalidad, interdependencia, indivisibilidad y progresividad". han obligado a repensar las formas tradicionales del estudio y aplicación del derecho constitucional, transformando la actividad jurisdiccional como vía de la consolidación del "Estado social y democrático de derecho".

\section{LA FIGURA JURISPRUDENCIAL DEL ESTADO DE COSAS INCONSTITUCIONAL (ECI) EN COLOMBIA}

Retomando el planteamiento del desarrollo de un constitucionalismo latinoamericano, la Carta Política Colombiana del año de 1991 adopta un modelo de Estado social de derecho, en el que el derecho a la igualdad y los derechos de prestación cobran una especial relevancia, al representar esa dimensión material a la que se ha hecho referencia en líneas anteriores, por lo que se precisa lo siguiente:
1) El diseño de Estado social de la nación colombiana (artículo 1).

2) Las obligaciones de respeto de los principios, derechos y obligaciones consagrados en la carta constitucional (artículo 2).

3) La obligación de generar condiciones de igualdad y sancionar omisiones (artículo 13).

4) La obligación institucional de colaborar de manera organizada para la consecución de sus objetivos (artículo 113).

5) La obligación de la adecuada conducción económica del Estado para cumplir con las metas propias del Estado social (artículo 334).

No obstante, en Colombia se presentó una lamentable situación en la que la vulneración masiva de derechos y la creciente exigibilidad a través de la garantía secundaria denominada “acción de tutela" provocó una saturación de las vías judiciales, sin que ello pusiera freno y fuera la solución a las afectaciones generalizadas a derechos fundamentales que sufrían los seres humanos. Fue entonces que la Corte Constitucional acuñó por vía de la emisión de una línea de sentencias la figura del ECI, teniendo el objetivo de identificar, generar las propuestas de reforma o modificación de las instituciones involucradas y contrarrestar las trasgresiones a los derechos humanos, a partir de un tratamiento que supone una revisión periódica, diferenciada y colaborativa por parte de las instituciones y órganos del Estado:

[E]sta Corporación ha hecho uso de la figura del Estado de Cosas Inconstitucional con el fin de buscar remedio a situaciones de vulneración de los derechos fundamentales que tengan un carácter general -en tanto que afectan a multitud de personas-, y cuyas causas sean de naturaleza estructural -es decir que, por lo regular, no se originan de manera exclusiva en la autoridad demandada $y$, por lo tanto, su solución exige la acción mancomunada de distintas entidades (Sentencia T-153/98 [MP. Eduardo Cifuentes Muñoz]).

Aquí es importante señalar, que el desarrollo jurisprudencial del ECI tiene sus orígenes en la emisión de la Sentencia SU-559-97, en la que la litis a resolver es en relación a una serie de afectaciones que resintieron los docentes a sus 
derechos fundamentales, esto por la negativa de su incorporación a un fondo de prestaciones, el cual derivaba en una afectación. Fue entonces que la Corte Constitucional formuló la expresión: "estado de cosas contrario a los preceptos constitucionales".

Como en todo desarrollo jurisprudencial, a lo largo de los años la guardiana de la Constitución continuó ampliando los alcances de dicha figura hasta llegar a establecer 6 condiciones para la declaración formal un ECI:

1) La vulneración masiva y generalizada de derechos constitucionales que afecten a un número significativo de personas.

2) La prolongada omisión de las autoridades en el cumplimiento de sus obligaciones.

3) La adopción de prácticas inconstitucionales, como la incorporación de la acción de tutela como parte del procedimiento para garantizar el derecho conculcado.

4) La no expedición de medidas legislativas, administrativas o presupuestales necesarias para hacer frente a dicha vulneración.

5) La existencia de un problema social cuya solución compromete la intervención de varias entidades.

6) La posible congestión judicial a partir de la promoción masiva de acciones de tutela para obtener la protección de derechos (Sentencia T-025/04 [MP. Manuel José Cepeda Espinosa], 2004).

Tales condiciones, han traído como consecuencia que los grupos afectados utilicen los mecanismos de garantía secundaria que ofrece el aparato judicial colombiano, pero sin encontrar una solución tampoco en esa vía, pues del análisis de las sentencias, las cuales veremos más adelante, la mayoría de las tutelas no corresponden a ser un mecanismo efectivo para la salvaguarda de los derechos fundamentales de un grupo masivo de personas, como lo es la propia acción de tutela. En consecuencia, se presenta un fenómeno complejo comenzando por la congestión y paralización del sistema jurisdiccional, sin que se logre la esperada reivindicación de derechos.

Cabe señalar que, ante los problemas visibles, los cuales son producto de una serie de omisiones de naturaleza administrativa, legislativa, presupuestal e incluso judicial, la Corte Constitucional ha reiterado que esas afectaciones masivas "exigen la acción mancomunada de distintas entidades" (Sentencia T-153/98 [MP. Eduardo Cifuentes Muñoz]). Ello justifica la exigibilidad de derechos frente a un conjunto de autoridades omisas que evaden sus obligaciones de proteger, respetar y garantizar los derechos, que encuentran fundamento en el bloque de constitucionalidad.

Asimismo, en el contexto del activismo judicial, valdría la pena analizar las acciones ordenadas en sus sentencias por distintos tribunales en otros países, evaluando el diseño e implementación de políticas públicas -dentro de las que se destaca la política criminal-, tal y como se describe a continuación:

[P]ara superar la crisis de superpoblación en el sistema penitenciario, la $H$. Corte Constitucional debe estudiar, analizar y considerar la tercera fase de la política criminal; esto es, el realizar estudios con relación a la liberación masiva de personas que se encuentren en reclusión, tomando como referencia lo que han hecho en Estados Unidos, especialmente en California en el año 2011, en donde una Corte Federal ha ordenado la liberación de presos como medida necesaria para poner solución a la violación de los derechos constitucionales de los presos, lo cual se viene exigiendo desde los años 1990 y 2001 (Huertas, R. Manrique, \& Benítez, 2019: 200).

Vale la pena destacar que el alto tribunal no agota su actuación con enfocar su trabajo y atención con la emisión de una sentencia, sino que, derivado del estado de cosas que generar múltiples crisis, se dedica a desplegar labores de supervisión de aquellas acciones de cumplimiento de la declaratoria dictada en sentencia, involucrando al resto de las instituciones y órganos del Estado, para consolidar el Estado social de derecho.

Con lo anterior, estamos en la posibilidad de afirmar que, la actuación desplegada por la Corte Constitucional aterriza las bases para la transformación de la muy lamentable realidad a la que hoy nos enfrentamos, al buscar la debida observancia de las obligaciones impuestas al Estado colombiano y sus autoridades, las cuales derivan del "corpus iuris de los derechos humanos"; 
asumiendo un rol regulador, verificador $\mathrm{y}$ colaborador con el resto de los poderes estatales.

\section{EL IMPULSO JURISPRUDENCIAL DEL ESTADO DE COSAS INCONSTITUCIONAL EN EL SISTEMA PENITENCIARIO Y CARCELARIO EN COLOMBIA}

En el siguiente apartado, se mostrará el desarrollo en línea jurisprudencial de la Corte Constitucional que ha trazado una línea significativa en la declaratoria del ECI, dentro del sistema penitenciario y carcelario, el cual servirá al lector de guía para conocer el desarrollo y evolución de tan importantes sentencias.

Se ha de advertir que las decisiones a analizar corresponden a un periodo que abarca más de quince años, y si bien es cierto, la Corte Constitucional se ha pronunciado en otras tantas sentencias al respecto del ECI; no obstante, fueron seleccionadas únicamente 6 decisiones atendiendo al desarrollo e implicaciones sustanciales que estas mismas aportaron al debate.

\subsection{ANÁLISIS DE LA SENTENCIA T-153/98}

La Sentencia T-153/98 develó por primera vez el problema jurídico que abordó la Corte Constitucional "al hacer un análisis de las condiciones en que se encontraban recluidas las personas que cumplían una pena dentro de las cárceles nacionales Modelo de Bogotá y Bellavista de Medellín" (Sentencia T-153/98 [MP. Eduardo Cifuentes Muñoz]), corroborando una vulneración a derechos humanos de miles de personas en reclusión de manera masiva y sistemática.

\section{Hechos relevantes}

La Sala Tercera de Revisión de la Corte Constitucional seleccionó las tutelas que presentaron los internos en contra del INPEC N. T-143950 y N. T-137001, "por lo cual se ordenó la práctica de inspecciones judiciales a las cárceles Modelo y Bellavista de Bogotá y Medellín, respectivamente. mediante estas inspecciones", la Sala de las visitas in situ tuvo conocimiento de las condiciones denigrantes en que se encontraban las personas sujetas a detención y que cumplen una pena en estos centros carcelarios.
De esta forma, en la cárcel La Modelo de Bogotá:

(...) la población asciende a 5000 internos; la existencia de un cobro ilegal para dormir en una celda; la restricción del servicio de agua y los evidentes problemas de alcantarillado; el hacinamiento en diversas áreas destinadas al esparcimiento, a los talleres, entre otras; la venta de drogas, armas y la práctica permanente de extorsiones; el cobro de impuestos para garantizar la autoprotección" (Sentencia T-153/98 [MP. Eduardo Cifuentes Muñoz]).

Por otra parte, lo que se encontró en la cárcel Bellavista de Medellín:

[F]ue que el número de internos asciende a 5125 internos; únicamente cuenta con un profesional en el área de psicología, una trabajadora social y 320 guardias; existe restricción del servicio de agua; hacinamiento: en áreas diseñadas para 4 personas habitan hasta 27 internos; celdas en las que la temperatura es elevada y no cuentan con ventilación; hacinamiento visible en áreas como patios, pasillos, baños, entre otras; y ausencia de un tratamiento penitenciario (Sentencia T-153/98 [MP. Eduardo Cifuentes Muñoz]).

\section{Principales argumentos}

La Sala Tercera de Revisión, que conoció del asunto, precisó de acuerdo con los informes que derivaron de las visitas in situ en los dos centros carcelarios se llegó a la conclusión que:

[L]as condiciones de reclusión en las dos cárceles citadas son absolutamente infrahumanas, indignas de una persona humana. Las condiciones de albergue de los internos son motivo de vergüenza para un Estado que proclama su respeto por los derechos de las personas y su compromiso con los marginados (Sentencia T-153/98 [MP. Eduardo Cifuentes Muñoz]).

Además la Sala Tercera en su análisis encontró e hizo énfasis en que "el problema no radica solamente en estos dos centros, sino que el hacinamiento carcelario es una situación generalizada que inclusive en otros centros se 
agrava todavía más" (Sentencia T-153/98), por lo que hace un pronunciamiento, los cuales se resumen en los siguientes puntos:

- La situación en las prisiones impide la resocialización de los reclusos, al no poder gozar de las condiciones mínimas para poder realizar el tratamiento.

- Se limitan aspectos básicos como el acceso al agua, servicios sanitarios, salud, incluso visitas familiares en condiciones decorosas, lo que erosiona la dignidad.

- Los derechos de los internos al debido proceso y al derecho de petición.

- No se brinda a los reclusos los medios necesarios para reincorporarse socialmente.

- La existencia notoria de un Estado de Cosas Inconstitucional en el sistema penitenciario, este no ha sido un tema que tenga importancia en la agenda política.

- Por esto, el juez constitucional, al ser un representante de los grupos vulnerables, se encuentra legitimado para exigir de las distintas ramas y órganos del poder la actuación necesaria para corregir ese Estado de Cosas Inconstitucional.

\section{Puntos resolutivos}

En atención a la situación que imperaba en la prisión y la cual era a todas luces evidente que contradecía el espíritu y mandatos constitucionales, la Sala Tercera de Revisión fijó dentro de su sentencia once puntos, entre los cuales podemos destacar por su importancia los siguientes:

- Notificar acerca de la existencia del Estado de Cosas Inconstitucional en las prisiones a múltiples autoridades de los poderes legislativo, ejecutivo y judicial, tanto del ámbito nacional como local.

- Ordena elaborar y ejecutar un plan de construcción y refacción carcelaria tendente a garantizar a los reclusos condiciones de vida dignas en los penales, y asigna responsabilidades de vigilancia (Procuraduría General de la Nación y Defensoría del Pueblo) y de modificaciones en el presupuesto para su financiamiento (Gobierno Nacional).

- Ordena al INPEC que recluya en establecimientos especiales a los miembros de la Fuerza Pública que se encuentran privados de la libertad, y que, en un término máximo de cuatro años, separe completamente los internos sindicados de los condenados.

\subsection{ANÁLISIS DE LA SENTENCIA T-256/00}

Surge de la revisión de resolución dictada por el Juzgado Dieciocho Penal del Circuito de Medellín, de ese análisis y modificación nace la Sentencia T-256-/00 (MP. José Gregorio Hernández Galindo), al pronunciarse en vía de revisión sobre la acción de tutela instaurada por "David Antonio Saldarriaga contra el director de la cárcel de Bellavista", la cual se dio en el sentido de "no conceder la protección de la tutela, argumentando que tales condiciones prevalecen dentro del centro carcelario de Bellavista hacen parte del sistema extramuros, es decir, el sistema social, político y económico que afronta el país" y cuyo efecto se nota más dentro de los establecimientos de reclusión.

Sobre la persona sujeta a detención, la Corte Constitucional señala que:

[S]e encuentra en una situación en la que se le ha vulnerado un conjunto de derechos, como la igualdad y la dignidad humana, y que estas violaciones son consecuencia del grave hacinamiento que prevalece al interior del centro carcelario. Así, afirma que se halla en condiciones infrahumanas...que le han ocasionado enfermedades infectocontagiosas que ha debido soportar sin la necesaria atención médica, pues la cárcel no cuenta con un servicio eficiente (Sentencia T-256/00 [MP. José Gregorio Hernández Galindo]).

La Sala Quinta de Revisión de la Corte Constitucional, al analizar la resolución antes referida, se basa en el argumento que "el recluso puede reclamar por vía de tutela la garantía de sus derechos fundamentales que no estén limitados por su condición de recluso". Además, reitera que "el sistema carcelario está obligado a brindar un trato acorde con la propia naturaleza humana; es decir, un trato digno, respetando en todo momento la integridad de las personas".

La Sala Quinta de Revisión resuelve finalmente:

- Ordenar al director de la cárcel de Bellavista proporcionar al recluso accionante un sitio adecuado y digno para su descanso y suministrarle los cuidados asistenciales 
y los medicamentos que requiera para el mantenimiento de su salud.

- Conminar al ministro de Justicia y del Derecho para que adelante los planes, obras y programas que le fueron encomendados en el fallo T-153/98 de la Corte Constitucional.

- Dar traslado al procurador General de la Nación y al defensor del Pueblo para que atiendan lo que esté dentro de sus competencias.

\subsection{ANÁLISIS DE LA SENTENCIA T-388/13}

La Sentencia T-388/13 (MP. María Victoria Calle Correa) se originó a partir de "la revisión de un conjunto de tutelas en nueve procesos, las tutelas que se presentaron y por el cual se buscaba la protección de la justicia, guardan características comunes", esto es, que estaban relacionadas con "la denuncia de violaciones de diferentes derechos en seis centros penitenciarios y carcelarios, a saber, los derechos a la dignidad humana, a la vida en condiciones dignas, a la integridad personal, a la salud, a la reintegración social de personas privadas de la libertad".

La Sala Quinta de Revisión al desarrollar su análisis jurídico, se plantea interrogantes con el fin de determinar con precisión los problemas a resolver:

¿Violan las autoridades acusadas por los diferentes accionantes [...] los derechos fundamentales de las personas privadas de la libertad, en especial a la dignidad humana, a la vida, a la salud y a la resocialización, en razón a las deplorables condiciones de reclusión [...], a pesar de que tal situación de los centros penitenciarios es un asunto estructural que no le compete, específicamente, a ninguna de las autoridades acusadas?

[...] ¿Debe un juez de tutela tomar medidas de protección concretas y específicas ante la solicitud de una persona privada de la libertad, por las violaciones a las cuales está siendo sometida en la actualidad [...], a pesar de que la Corte Constitucional ya se había pronunciado en el pasado al respecto, en una sentencia en la que declaró el Estado de Cosas Inconstitucional e impartió órdenes de carácter general?
La respuesta de la Sala de Revisión a la primera interrogante es afirmativa y recuerda que "[E]ste problema ya fue resuelto por la jurisprudencia constitucional", en cuanto a la segunda pregunta, la respuesta también es afirmativa, puesto que, "si bien existen similitudes entre el Estado de Cosas que motivó la declaratoria del Estado de Cosas Inconstitucional del año 1998 y el actual, se trata de contextos y supuestos fácticos diferentes".

\section{Principales argumentos}

Los principales argumentos de la Sala de Revisión de la Corte Constitucional para sostener que la crisis del sistema penitenciario y carcelario continua en un ECI que, lejos de superarse, se viene agravando, descansan en que

(...) el Estado no puede garantizar el acceso efectivo a un conjunto de derechos y condiciones básicas de los reclusos, para poder vivir dignamente se crean condiciones de indignidad, lo cual resulta contradictorio a un estado respetuoso de la Carta Internacional de Derechos, pues no puede, bajo ninguna circunstancia justificar, ni siquiera con el argumento de una reducida capacidad económica del Estado (Sentencia T-388/13 [MP. María Victoria Calle Correa]).

Por otra parte, la sala de revisión encuentra un fenómeno que tiene que ver con una serie de deficiencias que se vienen arrastrando a través del tiempo, al afirmar que el juez de tutela no puede, ni debe, excusarse de cumplir con sus obligaciones, "puesto que entre sus deberes están: 1) verificar la violación a los derechos alegada; 2) declarar que esta ocurre, en caso de que así se haya constatado; así como 3) informar y comunicar la situación". Aspectos que son importantes para el presente análisis, pues en las anteriores sentencias los jueces de tutela no hacían la verificación de los establecimientos carcelarios, lo cual hace visible las fallas y evidenció que la tutela no fuera un recurso efectivo para acabar con la violación de los derechos de las personas en reclusión.

De este modo, la sala de revisión hace patente:

[L]a importancia del activismo judicial y el papel proactivo que debe desempeñar el juez de tutela ante la condición particular de los reclusos que se traduce en desventajosa, por lo que le corresponde profundizar más allá de 
lo alegado para proteger de manera integral el grupo de derechos que se encuentran violentados (Sentencia T-388/13 [MP. María Victoria Calle Correa]).

\section{Puntos resolutivos}

La Sala de Revisión dictó en la sentencia veinticuatro puntos resolutivos, en los cuales:

[S]e ordena a un conjunto de autoridades e instituciones estatales que continúen tomando las providencias adecuadas, inmediatas $y$ necesarias para frenar el denominado ECI del sistema penitenciario y carcelario; también da diversas órdenes a cada una de las autoridades judiciales que conocieron de las acciones de tutela objeto de revisión de esa sentencia.

De la nueva la resolución nos llama la atención que no abandona las anteriores sentencias y retoma el desarrollo jurisprudencial T-153/98 y T-256/00, para darle especial seguimiento y sostener que:

- El sistema penitenciario y carcelario nuevamente está en un Estado de Cosas contrario a la Constitución Política de 1991.

- Se hace del conocimiento que la competencia de los jueces que decidieron en primera instancia cada una de las acciones de tutela objeto de revisión, para adelantar, de la mano con los auxiliares y colaboradores de la justicia, el cumplimiento de las órdenes impartidas. No obstante, la Corte Constitucional, se reserva la posibilidad de asumir el seguimiento al cumplimiento de alguna de estas órdenes (Sentencia T-388/13 [MP. María Victoria Calle Correa]).

\subsection{ANÁLISIS DE LA SENTENCIA T-815/13}

La Sentencia T-815/13 ([MP: Alberto Rojas Ríos) surge del proceso de revisión de un fallo de tutela instaurada por "el señor Deiler Enrique Santiago Romero y otros contra el Establecimiento Penitenciario y Carcelario de Bogotá La Picota y el Instituto Nacional Penitenciario y Carcelario", quienes de manera reiterada amenazan y ponen en situación de seria amenaza sus derechos humanos a través de "sus estructuras directivas, providencias $\mathrm{y}$ actos de tipo restrictivo $\mathrm{y}$ limitativo", mediante las siguientes acciones:
- Son obligados a recibir a sus esposas, hijos y demás familiares y amigos en condiciones indignas y en lugares no adecuados.

- La visita íntima se recibe en condiciones indignas y violatorias del derecho a la intimidad, toda vez que solo existen veinte celdas para visita conyugal o íntima.

- Existe un trato desigual y discriminatorio con respecto a las visitas que reciben los internos condenados por parapolítica 0 exmiembros de la Fuerza Pública.

Sin embargo, el Juez Diecisiete Penal del Circuito de Bogotá D. C. con Función de Conocimiento estimó de manera errónea que:

[L]a acción de tutela no es el instrumento jurídico idóneo para solucionar apuros nacidos por el despacho de actos administrativos de los entes públicos y sostuvo que el hacinamiento carcelario no es una situación de ahora, sino que ha permanecido por varios años y, por lo tanto, se trata de un problema estructural (Sentencia T-815/13 [MP: Alberto Rojas Ríos], 2013).

Quizá el análisis para abordar ello hubiera sido la capacidad para afrontar ese problema estructural, pero no fue así; por esos argumentos, la sala de revisión se planteó el analizar si las condiciones en que se encuentran las personas en reclusión obedecen a "los estándares de dignidad que garantizan un conjunto de derechos fundamentales que presuntamente han sido quebrantados (derechos a la salud, a la intimidad, a la integridad física y/o psicológica y a la igualdad)". En atención a ello, la Sala se pronuncia sobre:

1) los derechos fundamentales de las personas que se encuentran en estado de reclusión; 2) el régimen de visitas y la visita íntima en condiciones dignas; 3) los derechos sexuales de los reclusos y el derecho a la salud; y 4) el análisis del caso en concreto de acuerdo con las solicitudes hechas por los accionantes (Sentencia T-815/13 [MP: Alberto Rojas Ríos], 2013).

\section{Principales argumentos}

La Sala Octava de Revisión de la tutela instaurada procedió a un análisis minucioso de 
las situaciones puestas a consideración por los reclamantes y precisó que:

[L]a población privada de la libertad se encuentra bajo la protección del Estado. Por lo cual, las autoridades están encargadas de vigilar el respeto y garantía de los derechos de cada una de las personas que conforman tal población, colocando especial atención en la vida, la salud, la integridad tanto en su dimensión física y moral y todas las demás condiciones necesarias para una vida digna.

[...] [L]es corresponde a las entidades estatales correspondientes evitar la extensa y continua afectación de derechos fundamentales de los reclusos, sin que la ausencia de presupuesto estatal justifique esa situación, ya que el Estado está obligado a proporcionar las condiciones mínimas y además necesarias para poder respetar y garantizar la vida digna de las personas recluidas en la red de establecimientos carcelarios del país (Sentencia T-815/13 [MP: Alberto Rojas Ríos], 2013).

Un aspecto relevante en la sentencia es que hace un pronunciamiento con respecto a "las condiciones necesarias en que debe llevarse a cabo la práctica de la visita íntima”, atendiendo a una garantía que debe de ser satisfecha por las autoridades penitenciarias. Con ello se pretende que tanto los derechos del recluso como de su pareja, no sean motivo de afectación, tal y como venía ocurriendo; estas condiciones son la "privacidad, seguridad, higiene, espacio, mobiliario, acceso a agua potable, uso de preservativos e instalaciones sanitarias", por lo que reitera la necesidad de la protección constitucional de los derechos de la sexualidad de los reclusos y de sus parejas.

\section{Puntos resolutivos}

La Sala Octava señaló diez mandatos a las autoridades responsables, entre los cuales se pueden hacer énfasis en los siguientes:

- Revoca la sentencia proferida por el Juzgado Diecisiete Penal del Circuito con Función de Conocimiento de Bogotá D.C. que denegó la acción de tutela de la referencia y concede la protección de los derechos fundamentales a la vida digna, a la intimidad, al agua, a la salud, a la integridad física y psicológica y al buen trato a favor de los accionantes.

- Ordena que la prestación de los servicios médicos en la cárcel La Picota se brinde por personal médico proporcional y suficiente y que se suministren mínimo dos preservativos por interno.

- Ordena al Ministerio de Hacienda, al Ministerio de Justicia y del Derecho, al Departamento Nacional de Planeación y al Instituto Nacional Penitenciario y Carcelario que se realicen las gestiones administrativas y apropiaciones presupuestales necesarias para iniciar las obras de infraestructura requeridas, con el fin de que las visitas conyugales o íntimas se practiquen en condiciones dignas (Sentencia T-815/13 [MP: Alberto Rojas Ríos], 2013).

\subsection{ANÁLISIS DE LA SENTENCIA T-861/13}

La Sentencia T-861/13 (MP: Alberto Rojas Ríos) resultó de la revisión de tutela pronunciado por el "Juzgado Promiscuo del Circuito de Jericó, Antioquia”, la acción de tutela fue interpuesta por "Edwin Arango Restrepo en contra del Instituto Nacional Penitenciario y Carcelario (INPEC) y el Establecimiento Penitenciario de Mediana Seguridad y Carcelario de Jericó, Antioquia”.

El accionante manifiesta "estar internado en el Establecimiento Penitenciario y Carcelario de Mediana Seguridad de Jericó, Antioquia, el cual posee una estructura para albergar a 53 internos; sin embargo, dentro del sitio se encuentran 141 internos", lo que trae como consecuencia una gran concentración de población dentro del establecimiento, lo cual resulta en una afectación a los derechos no solo del accionante, sino de la población en general . Por esta razón, "el accionante solicita tutelar sus derechos fundamentales y declarar que el INPEC y la cárcel de Jericó, Antioquia, vulneran sus derechos a la salud y a la vida en condiciones dignas"; por ello, pide dentro de su demanda a las autoridades, que se abstengan de continuar admitiendo a nuevos reclusos en calidad de sindicados o condenados, pues no existen las condiciones ni mucho menos la capacidad para atenderlos, por el contrario dentro de sus exigencias que solicita, es que se adopten las medidas necesarias para la reubicación de los reclusos en aras de descongestionar el hacinamiento que se padece. En respuesta: 
[El] Juzgado Promiscuo del Circuito de Jericó, Antioquia, protegió los derechos fundamentales a la vida y a la salud solicitados por el accionante; por este motivo, se ordena al director del INPEC la evacuación de los condenados que sean necesarios para que únicamente se albergue de 100 a 110 presos (Sentencia T-861/13 [MP: Alberto Rojas Ríos]).

La Sala Octava de Revisión señaló que:

[E]l problema jurídico a resolver es determinar si la decisión del juez que ordenó desalojar a los condenados que sean necesarios para que en el centro de reclusión accionado se mantengan únicamente cien internos protege constitucionalmente los derechos fundamentales a una vida digna y a la salud, derechos que fueron invocados y parte del argumento central del accionante (Sentencia T-861/13 [MP: Alberto Rojas Ríos]).

En ese sentido, la Sala se pronunció sobre estos puntos:

1) los derechos de las personas que se encuentran en estado de reclusión;

2) el hacinamiento y el derecho fundamental a la integridad personal; $y$

3) el análisis del caso en concreto con soluciones que protejan de inmediato los derechos fundamentales presuntamente vulnerados.

\section{Principales argumentos}

En esta sentencia, la Sala de Revisión advierte que:

[A]ún cuando el juez actuó de manera proactiva frente la necesidad de protección de los derechos básicos, cometió el error de fijar de manera subjetiva el cupo total y máximo, puesto que no hay argumentos que demuestren razonabilidad y proporcionalidad en la decisión, por lo que esta no protege de manera integral los derechos de los demandados (Sentencia T-861/13 [MP: Alberto Rojas Ríos]).

Además, la sala de revisión destacó que "durante el traslado de reclusos, las autoridades tienen la obligación de priorizar el desplazamiento de aquellas personas que impliquen menor peligrosidad, y "de coordinar con la Fuerza Pública para garantizar la máxima seguridad de ese local provisional".

\section{Puntos resolutivos}

La sentencia de la Sala Octava de Revisión de la Corte Constitucional, ordena lo siguiente:

- Revoca parcialmente la sentencia proferida por el Juzgado Promiscuo del Circuito de Jericó, Antioquia respecto a la tutela mencionada.

- Tutela los derechos fundamentales a la vida digna, a la salud y a la integridad física y psicológica del ciudadano Edwin Arango Restrepo recluido en el Establecimiento Penitenciario de Mediana Seguridad y Carcelario de Jericó, Antioquia.

- Ordena al Ministerio de Hacienda, al Ministerio de Justicia y del Derecho y al INPEC que realicen las gestiones administrativas $y$ presupuestales necesarias con el fin de iniciar las obras de infraestructura requeridas para eliminar el problema de sobrecupo carcelario que presenta el Establecimiento Penitenciario de Mediana Seguridad y Carcelario de Jericó, Antioquia.

- Ordena al director general del INPEC, al gobernador de Antioquia y a los alcaldes municipales de Jericó, Pueblorrico y Tarso, Antioquia, que se reúnan con el fin de llegar a un acuerdo respecto a la búsqueda y el arrendamiento de un local donde puedan ser recluidos algunos internos en condiciones de dignidad humana, seguridad y espacio adecuado (Sentencia T-861/13 [MP: Alberto Rojas Ríos]).

\subsection{ANÁLISIS DE LA SENTENCIA T-762/15}

La Sentencia T-762/15 (MP. Gloria Stella Ortiz Delgado), revisa los fallos dictados en dieciocho expedientes; el problema jurídico identificado y que ocupa a la Sala Quinta de Revisión es "evaluar la existencia del Estado de Cosas Inconstitucional”, por esto, se plantea la necesidad de esclarecer:

1) si los derechos fundamentales de los actores se encuentran comprometidos por las condiciones de reclusión a las que se encuentran sometidos; 
2) si es suficiente la emisión de una orden judicial que comprometa a los accionados, particularmente considerados, o si es necesaria la gestión de un conjunto sistemático y coordinado de acciones para contener la vulneración de los derechos de los accionantes; y, de contera;

3) si se verifican actualmente las condiciones que generaron la declaratoria del Estado de Cosas Inconstitucional en el sistema penitenciario y carcelario del país en 2013 (Sentencia T-762/15 [MP. Gloria Stella Ortiz Delgado]).

\section{Principales argumentos}

La Sala de Revisión señala, que ante "el reiterado Estado de Cosas Inconstitucional en el sistema penitenciario y carcelario, el enfoque de su resolución está encaminado hacia la política criminal", pues las medidas de contención son insuficientes, de allí que para alcanzar mayor eficacia se centra en corrección de políticas públicas, tal como lo es la criminal.

De este modo, la sala de revisión identifica las problemáticas comunes en las tutelas revisadas:

1) "política criminal inconstitucional;

2) hacinamiento y otras causas de violación masiva de derechos;

3) reclusión conjunta de condenados y sindicados;

4) deficiente sistema de salud en el sector penitenciario y carcelario, y

5) inadecuadas condiciones de salubridad e higiene en el establecimiento penitenciario $\mathrm{y}$ en el manejo de alimentos (Sentencia T-762/15 [MP. Gloria Stella Ortiz Delgado]).

Posteriormente, se propone "el estándar mínimo, con apego al marco constitucional, que debe cumplir el desarrollo e implementación de una política criminal colombiana, la cual debe estar apegada al irrestricto cumplimiento $y$ observancia de los derechos humanos".

Así desde la óptica del juzgador, la política criminal:

[D]ebe tener un carácter preventivo, uso del derecho penal como última ratio; debe respetar el principio de la libertad personal, de forma estricta y reforzada; debe buscar como fin primordial la efectiva resocialización de los condenados; las medidas de aseguramiento privativas de la libertad deben ser excepcionales; debe ser coherente; debe estar sustentada en elementos empíricos; debe ser sostenible; medición de costos en derechos económicos y debe proteger los derechos humanos de los presos (Sentencia T-762/15 [MP. Gloria Stella Ortiz Delgado]).

\section{Puntos resolutivos}

La Sala Quinta que hace la revisión de tutela, emite un amplio número de puntos que involucran una serie de acciones y de actuaciones de las instituciones involucradas, entre los que se destacan los siguientes:

- Reiterar la existencia de un Estado de Cosas contrario a la Constitución Política de 1991 en el sistema penitenciario y carcelario del país, declarado mediante la sentencia T-388 de 2013.

- Declara que la política criminal colombiana ha sido reactiva, populista, poco reflexiva, volátil, incoherente y subordinada a la política de seguridad.

- Ordena al Congreso de la República, al Gobierno nacional, a la Fiscalía General de la Nación que den aplicación al estándar constitucional mínimo de una política criminal respetuosa de los derechos humanos, cuando se propongan, inicien o tramiten proyectos de ley 0 actos legislativos que incidan en la formulación y diseño de la política criminal, en el funcionamiento del sistema de justicia penal $y / o$ en el funcionamiento del sistema penitenciario y carcelario.

- Exhorta al Congreso de la República, al Gobierno nacional y a la Fiscalía General de la Nación para que promuevan la creación, implementación y/o ejecución de un sistema amplio de penas y medidas de aseguramiento alternativas a la privación de la libertad.

- Exhorta al Congreso de la República y al Ministerio de Justicia y del Derecho a revisar el sistema de tasación de las penas en la legislación actual, con el fin de identificar sus incoherencias e inconsistencias, de acuerdo con el principio de proporcionalidad de la pena, y tomar los correctivos del caso.

- Dispone que el Gobierno nacional deberá adoptar las medidas adecuadas y necesarias para asegurar los recursos suficientes y oportunos que permitan la sostenibilidad 
y progresividad de todas las medidas a implementar para dar cumplimiento a lo ordenado en esta sentencia (Sentencia T-762/15 [MP. Gloria Stella Ortiz Delgado]).

\section{CONCLUSIONES}

Con lo dicho hasta aquí, hemos advertido la importancia del activismo judicial de la Corte Constitucional en los últimos años, reconocemos en la emisión de la declaratoria del ECI dentro del sistema penitenciario y carcelario, el protagonismo del juez y el impacto de sus desarrollos jurídicos innovadores para alcanzar y materializar los derechos consagrados en el plano constitucional, los cuales sirven como remedio y limitación a la violación sistematizada y generalizada de derechos, ya sea por acción u omisión de las instituciones y autoridades carcelarias y penitenciarias.

Con esa figura, la Corte ha declarado la existencia de esta situación en el sistema penitenciario y carcelario porque ha sido capaz de identificar las causas "generales" que permiten una violación sistemática, perenne y grave a un conjunto de derechos primordiales de las personas que están en reclusión dentro de las prisiones y centros de detención administrados por el Gobierno. "No significa que sean de menor envergadura en la agenda política, legislativa las problemáticas derivadas del hacinamiento y la grave crisis del sistema" (Archila \& Hernández, 2015: 202), motivos por los cuales las personas sujetas privadas de la libertad han demandado por vía judicial que un conjunto de autoridades estatales desplieguen una serie de acciones en el corto y mediano plazo para dar tratamiento a la situación y buscar medidas que tiendan a revertir esas violaciones y superar el estado de cosas que los mantiene bajo una condición infrahumana.

No cabe duda de que la declaratoria del ECI ha permitido visibilizar y poner en el centro de la atención a la exigente demanda de justicia por parte de los sectores de la población más vulnerable, afectada por las acciones u omisiones de autoridades en Colombia; en el caso que nos ocupa, de la población penitenciaria. Esta declaratoria muestra cómo los pronunciamientos judiciales analizados en el estudio han encausado esfuerzos nobles y legítimos para la reforma, reconstrucción, reorganización o ajuste de las instituciones penitenciarias y carcelarias, las cuales se realizan mediante el diálogo, la coordinación, supervisión y la evaluación constante para efecto de poder superar aquellas falencias estructurales que pueden ser las causas de un patrón de abusos de los derechos más básicos de las personas sujetas a reclusión.

La Corte Constitucional mediante la emisión de las sentencias ha reiterado que la solución del ECI en el sistema carcelario y penitenciario requiere de la suma de esfuerzos, en los que se debe de involucrar la actuación conjunta y coordinada de todas las autoridades estatales para revertirlo "ejecutivas, legislativas, judiciales, autónomas, etc. Así como de aquellas privadas, asociaciones civiles, religiosas y educativa, etc. Pues los desafíos vigentes en el sistema penitenciario requieren de un gran activismo, en especial de los jueces, lo cuales tienen el mandato de ser los auténticos guardianes de los derechos humanos y exigir en todo momento la materialización de estos.

Esa exigencia se traduce en una mayor intervención e interacción con el resto de las autoridades mientras persista la amenaza, pues, para superar esas fallas, se requiere de esfuerzos conjuntos dentro de un periodo de tiempo prolongado en el que se consiga desarrollar una importante reforma que pueda dar tratamiento a los factores contextuales y estructurales: limite en la materialización y efectividad de los derechos y aspiraciones que Colombia, como nación, se ha planteado alcanzar desde la Constitución de 1991.

En atención a ese activismo, el Grupo de Investigación a cargo del presente estudio ha propuesto a la Corte Constitucional desarrollar la implementación de la categoría "Política Criminal Sistémica" ${ }^{3}$, orientada a decantar las múltiples percepciones que se tienen acerca de ella y busca generar de lege ferenda propuestas estructurales que puedan ser utilizadas por el legislador al momento de producir normas sobre el tema carcelario y penitenciario, en perspectiva de la protección de los derechos humanos.

Para finalizar, resulta innegable que en Colombia, la población sujeta a detención o condena se encuentra en serio riesgo por la situación grave de hacinamiento que prevalece, por la deficiente alimentación y el estado de

3. Ver "Política Criminal Sistémica Origen Rizomático y Contribuciones para su Desarrollo" (Huertas, 2019). 
desnutrición que padecen los internos -en especial las madres gestantes, lactantes y personas de edad avanzada-, por contar con una población con enfermedades preexistentes y por la incapacidad de las autoridades penitenciarias de brindar espacios suficientes y adecuados para garantizar la salud de los internos, lo cual, supone un riesgo.

De allí que, en Colombia las autoridades nacionales y esa Corte Constitucional no deben permitir que se continúe poniendo en peligro valores superiores $y$ fundamentales de las personas en reclusión, pues mantener el ilegal hacinamiento involucra poner en serio riesgo la salud, la integridad física y la vida de cientos de personas que se encuentran en condiciones de reclusión y del personal penitenciario; sobre todo, mantener a personas en hacinamiento, es poner en riesgo a la población en general.

Si no hay una actuación inmediata por parte del gobierno colombiano, estos serán responsables de la violación constitucional por la afectación a la salud, integridad personal e incluso por la pérdida masiva de la vida de personas en situación de reclusión, lo cual sería una tragedia. Será entonces demasiado tarde para atender una crisis anunciada y olvidada.

\section{BIBLIOGRAFÍA}

- Archila, J., \& Hernández, N. (2015). Subrogados y hacinamiento carcelario, respuesta del legislador del año 2014 frente a la situación carcelaria en Colombia. Revista Misión Jurídica, 8 (9): 199 - 227.

- Benítez, C. (2014). Un acercamiento a los retos de los jueces mexicanos ante el control difuso de constitucionalidad/ convencionalidad. En J. Cabrera, D. Montero, \& H. González (Edits.), La reforma constitucional en materia de derechos humanos y su impacto en la sociedad. México: Fontamara.

- Benítez, C. (2013). México - Colombia: dos décadas de distancia del nuevo constitucionalismo latinoamericano. Revista Derecho y Sociedad, (6): 165 - 182.

- Bernal, C. (2005). El derecho de los derechos. Bogotá: Universidad Externado de Colombia.

- Crawford, C., \& Bonilla, D. (2018). Constitutionalism in the Americas. UK: Edward Elgar.

- Ferrajoli, L. (2012). Constitucionalismo principialista y constitucionalismo garantista. En M. Atienza (Ed.), Un debate sobre constitucionalismo. Madrid: Marcial Pons.
- Ferrajoli, L. (2018). Constitucionalismo más allá del estado. Madrid: Trotta.

- Fiss, 0. (2013). Los mandatos de la justicia. Madrid: Marcial Pons.

- Gómez, L. \& León, M. (2015). De los derechos ambientales a los derechos de la naturaleza: racionalidades emancipadoras del derecho ambiental y nuevas narrativas constitucionales en Colombia, Ecuador y Bolivia. Revista Misión Jurídica, 9 (10): 233-260.

- Guastini, R. (2010). Teoría e ideología de la interpretación constitucional. Madrid: Trotta.

- Huertas, O. (2019). Política Criminal Sistémica Origen Rizomático y Contribuciones para su Desarrollo. Bogotá: Ibáñez.

- Huertas, O., R. Manrique, F., \& Benítez, C. (Edits.). (2019). Análisis del estado de cosas inconstitucional en el sistema penitenciario y carcelario en Colombia Propuestas para el Estado Social de Derecho. Bogotá: Universidad Nacional de Colombia Universidad Pedagógica y Tecnológica de Colombia.

- Jiménez, W. (2008). Entre reglas y principios. Revista Misión Jurídica, 1(1): 15 $-50$. 
- López, D. E. (2006). El derecho de los jueces (2 ed.). Bogotá: Legis.

- Mejía, 0. (2012). Dos décadas de la constitución del 91: cronología de una constitución sitiada. En Memorias del XI Congreso Nacional de Filosofía del Derecho y Filosofía Social. constitucionalismo, pobreza y globalización. Bogotá: Universidad Libre.

- Prieto, L. (2013). El constitucionalismo de los derechos. Ensayos de filosofía jurídica. Madrid: Trotta.

- R. Manrique, F., \& Huertas, O. (2018). Una mirada comparada del estado de cosas inconstitucional en Colombia (ECI) vis à vis el mandato estructural en usa (The structural injunction). En: Estudios actuales del Derecho: la investigación como eje de transformación social. Sello Editorial Coruniamericana.

- Sager, L. (2013). Cortes constitucionales, derechos sociales y el "espacio de colaboración" entre el significado y la doctrina. En J. C. Henao (Ed.), Diálogos constitucionales de Colombia con el mundo. VII Encuentro de la jurisdicción constitucional. Bogotá, D.C: Universidad del Externado de Colombia.

- Sentencia T-025/04 [MP. Manuel José
Cepeda Espinosa] [Corte Constitucional de Colombia. Sala Tercera de Revisión 22 de enero de 2004).

- Sentencia T-153/98 [MP. Eduardo Cifuentes Muñoz] (Corte Constitucional de Colombia. Sala Tercera de Revisión 28 de abril de 1998).

- Sentencia T-256/00 [MP. José Gregorio Hernández Galindo] (Corte Constitucional de Colombia, Sala Quinta de Revisión 6 de marzo de 2000).

- Sentencia T-388/13 [MP. María Victoria Calle Correa] (Corte Constitucional de Colombia, Sala Primera de Revisión 28 de junio de 2013).

- Sentencia T-762/15 [MP. Gloria Stella Ortiz Delgado] (Corte Constitucional de Colombia, Sala Quinta de Revisión, 16 de diciembre de 2015).

- Sentencia T-815/13 [MP: Alberto Rojas Ríos] (Corte Constitucional de Colombia, Sala Octava de Revisión 13 de noviembre de 2013).

- Sentencia T-815/13 [MP: Alberto Rojas Ríos] (Corte Constitucional de Colombia, Sala Octava de Revisión 27 de noviembre de 2013). 